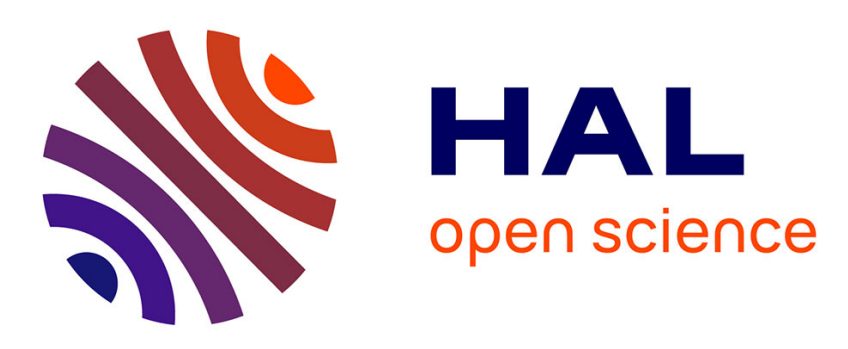

\title{
RNA-mediated non-mendelian inheritance of an epigenetic change in the mouse.
}

Minoo Rassoulzadegan, Valérie Grandjean, Pierre Gounon, Stéphane Vincent, Isabelle Gillot, François Cuzin

\section{- To cite this version:}

Minoo Rassoulzadegan, Valérie Grandjean, Pierre Gounon, Stéphane Vincent, Isabelle Gillot, et al.. RNA-mediated non-mendelian inheritance of an epigenetic change in the mouse.. Nature, 2006, 441 (7092), pp.469-74. 10.1038/nature04674 . hal-00166237

\section{HAL Id: hal-00166237 https://hal.science/hal-00166237}

Submitted on 3 Aug 2007

HAL is a multi-disciplinary open access archive for the deposit and dissemination of scientific research documents, whether they are published or not. The documents may come from teaching and research institutions in France or abroad, or from public or private research centers.
L'archive ouverte pluridisciplinaire HAL, est destinée au dépôt et à la diffusion de documents scientifiques de niveau recherche, publiés ou non, émanant des établissements d'enseignement et de recherche français ou étrangers, des laboratoires publics ou privés. 


\section{RNA-mediated non-Mendelian inheritance of an epigenetic change in the mouse}

Minoo Rassoulzadegan ${ }^{1}$, Valérie Grandjean ${ }^{1}$, Pierre Gounon ${ }^{2}$, Stéphane Vincent ${ }^{1}{ }^{\dagger}$, Isabelle Gillot ${ }^{1}$ \& François Cuzin ${ }^{1}$

1 Unité 636 de l'INSERM, Université de Nice-Sophia Antipolis, 06108 Nice cedex, France.

2 Centre Commun de Microscopie Appliquée, Université de Nice-Sophia Antipolis, 06108 Nice cedex, France.

${ }^{\dagger}$ present address: Unité de Génétique Moléculaire du Développement, Institut Pasteur, 75724 Paris cedex, France 
Paramutation is a heritable epigenetic modification induced in plants by a cross-talk between allelic loci. We report a similar modification of the Kit gene of the mouse in the progeny of heterozygotes with the null mutant $\mathrm{Kit}^{\text {tmlAlf }}$ ( LacZ insertion). In spite of a homozygous wild type genotype, their offspring maintain to a variable extent the white spots characteristic of Kit mutants. Efficiently inherited from both male and female parents, the modified phenotype results from a decrease in Kit mRNA with the accumulation of non-polyadenylated RNA molecules of abnormal sizes. Sustained transcriptional activity at the postmeiotic stages at which the gene is normally silent leads to the accumulation of RNA in spermatozoa. Microinjection into fertilized eggs either of total RNA from $\mathrm{Kit}^{\text {tmlAlf }}$ heterozygotes or of Kit specific microRNAs induced a heritable white tail phenotype. Our results identify an unexpected mode of epigenetic inheritance associated with the zygotic transfer of RNA molecules. 
Paramutation, first observed in maize ${ }^{1}$ and subsequently in a variety of plants $^{2}$, is a heritable epigenetic change of the phenotype of a "paramutable" allele, initiated by interaction in heterozygotes with a "paramutagenic" form of the locus. Often referred to as an exception to the law of Mendel, which states that genetic factors segregate unchanged from heterozygotes, paramutation is meiotically stable and inherited in the absence of the inducing allele. To date, the closest observations in an animal species were changes in the DNA methylation profiles directed by the allelic locus in the mouse that we and others described as "transvection" or "paramutation-like" effects" 3 . We now report a modification in the phenotypic expression of the wild type allele of the Kit receptor gene in the progeny of heterozygotes with a null insertion mutant. The "paramutated (Kit*)", genotypically wild type animals, maintain the white-spotted phenotype characteristic of Kit mutants in the absence of the mutant allele. The efficient paternal and maternal inheritance of the paramutated state raises the question of a possible molecular support of the epigenetic information.

\section{Non-Mendelian phenotype distribution}

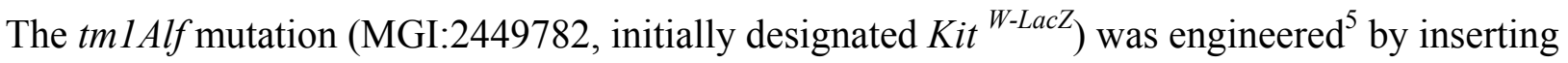
a $3 \mathrm{~kb}$ Neo-LacZ cassette downstream of the initiator ATG. A unique mRNA of the same size with the $ß$-galactosidase coding sequence is expressed under control of the Kit promoter and regulatory sequences. The mutation abrogates the synthesis of the Kit tyrosine kinase receptor, which plays a critical role in several developmental processes including germinal differentiation, hematopoiesis and melanogenesis. Accordingly, Kit ${ }^{{ }^{t m} l \mathrm{Alf}}$ homozygotes die shortly after birth and heterozygotes show a white tail tip and white feet (Fig. 1). We initially observed an abnormal segregation of phenotypes in the progeny of crosses between two heterozygous parents. Wild type genotypes were identified by the absence of both $L a c Z$ sequences determined by genomic PCR analysis and $\beta$-galactosidase expression by in situ X-Gal staining (not shown), and further confirmed by Southern blot analysis (Fig. 1c). However, it was striking that most of these genetically $\mathrm{Kit}^{+/+}$mice maintained the white patches characteristic of the parental heterozygotes (Fig. 1 and Table 1). The occurrence of this modified, "paramutated" form of the $\mathrm{Kit}^{+}$allele (Kit* phenotype) was not restricted to the progeny of heterozygote intercrossing, but also observed in $\mathrm{Kit}^{\mathrm{tm} \mathrm{lAlf} /+}$ crosses with wild type partners, 
independently of the gender combination (Table 1). It was not dependent on the genetic background of the mice since the same phenotypes were found with the original 129/Sv Kit ${ }^{\text {tmlAlf } /+}$ heterozygotes and after at least 6 generations of back-crosses of the mutation onto the $\mathrm{C} 57 \mathrm{Bl} / 6$ and B6D2 genetic backgrounds (Supplementary Table 1). The paramutated phenotype was inherited, with a variable phenotypic extent depending on the crosses (Supplementary Fig. 1). It was most strongly expressed in second generation crosses between Kit $^{{ }^{t m l A l f} /+}$ heterozygotes and still clearly recognizable in the progeny of Kit* parents in the absence of the tmlAlf allele (Kit* $\mathrm{x}$ Kit ${ }^{+/+}$and Kit* $\mathrm{x}$ Kit* crosses, Table 1 and Supplementary Fig. 1). It would then progressively disappear in the following generations.

Another feature apparent from the data in Table 1 (see also Supplementary Fig. 1) is that in crosses between heterozygotes, the Kit ${ }^{\text {tmlAlf/+ }}$ genotype was generated with frequencies in the range of 50 to 60 per cent, instead of the Mendelian two thirds. A likely explanation is that a fraction of the

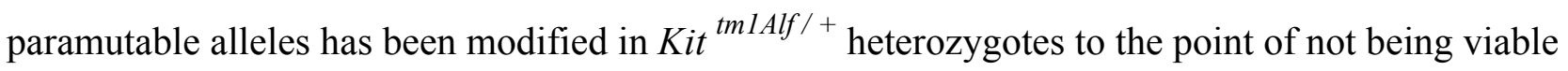
any more. The extent to which expression of the wild type allele is altered varies between individuals, as indicated by the variable extent of the white fur patches (see Supplementary Fig. 1), and either the lack or an extensively reduced level of receptor expression would not be compatible with normal development.

To probe the molecular basis of the paramutated phenotype, DNA and histone methylation were investigated in a CpG-rich region (nt. -31 to +219 ) which corresponds to the minimal Kit promoter ${ }^{6}$. Cytosine methylation was examined by amplification and sequencing after bisulfite treatment ${ }^{7}$. Possible changes in chromatin structure were investigated by chromatin immunoprecipitation with antibodies directed against the lysine 4 and 9 dimethylated forms of histone H3, which are respectively associated with active and repressed chromatin ${ }^{8}$. No significant change in either cytosine or histone methylation was observed between wild type, heterozygous and paramutated animals (data not shown). However, we cannot exclude a critical role of differential DNA or histone methylation either in a specific cell type or in one of the more distant and not yet precisely mapped control regions which had been inferred from the analysis of Kit mutants ${ }^{9}$. 


\section{Reduced levels of polyadenylated RNA}

The White-Spotted phenotype of heterozygotes of a null mutant and a wild type allele results from the reduced level of receptor expression ${ }^{5}$. This was also the case of paramutated animals. Levels of polyadenylated Kit mRNA amounting to one-half of the wild type homozygote were determined both in Kit $^{\text {tmlAlf } /+^{+}}$heterozygotes and in their paramutated (Kit*) progeny, despite the presence in the latter of two structurally normal wild type alleles (Fig. 2a). In addition to this marked decrease in mature mRNA, Kit RNAs of abnormal sizes accumulated, whose possible origin - abnormal arrest and/or initiation of primary transcription, abnormal post-transcriptional processing, secondary cleavage of mature RNAs - remains to be determined. Starting in heterozygotes, distinct profiles of abnormal fragments were seen in different tissues. As examplified in Fig. $2 \mathrm{~b}$, a prominent $0.37 \mathrm{~kb}$ RNA species was detected in brain RNA, identified (data not shown) as a spliced fragment of the mature Kit transcript including only exons 1 and 2. In the testis, Northern analysis detected a more dispersed smear of RNA molecules of multiple sizes. Since these abnormal short species were identified with a 5' probe corresponding to the region disrupted by LacZ insertion, and, on the other hand did not hybridize with a LacZ probe, it is clear that they were derived from the genetically wild type allele responsible for the Kit* phenotype. They were clearly distinct from the transcript limited to the $L a c Z$ coding region expressed from the mutant allele (Fig. 2b).

\section{RNA in Kit $^{\text {tm1 Ilf/+ }}$ sperm}

The next question that we addressed was the nature of the signal leading to the hereditary transfer of the paramutated state, first by a comparative analysis of spermatogenesis in the heterozygote and wild type testis. A significant difference was noted in Kit transcription levels, with higher levels determined by run-on assays in heterozygotes (Fig. 3a). Deregulation was most obvious at the late spermatogenic stages. In the wild type mouse, Kit transcription is essentially restricted to spermatogonia, with reduced levels in early meiotic cells ${ }^{10-13}$. The gene is virtually silent in the haploid phase, with the exception of a shorter RNA (tr-Kit) made from an internal promoter in the most 3 ' region of the locus ${ }^{14}$. In contrast, in Kit ${ }^{\text {tmlAlf } /+}$ germ cells, Northern blot analysis showed significant amounts of 5' Kit RNA sequences in both round and elongated spermatids (Fig. 3b). This 
altered pattern of expression included an increased activity of both the upstream Kit and the internal tr-Kit promoters. It also affected the promoters on the two alleles, as high levels of ß-galactosidase synthesis were evidenced in the haploid compartment of the tubules (Supplementary Fig. 2). These changes, clearly characteristic of heterozygous state, at which paramutation is initiated, may be related with meiotic mispairing. Such an effect would be contrasting with the equally unexplained decrease in expression due to a perturbed synapsis described in a recent report ${ }^{15}$.

Most likely as a consequence of its deregulated expression, Kit RNA was detected not only in the spermatids of heterozygotes and paramutated mice, but even more unexpectedly in their mature epididymal sperm (Fig. 4). Both semi-quantitative RT-PCR and quantitative real time PCR detected in sperm extracts RNA sequences corresponding to the 5' region of the gene. RT-PCR performed with only 20 cycles detected the Kit RNA sequences (Fig. 4a), in addition to other transcripts (including Gapdh, Prm1, Prm2) (data not shown). These RNAs were never detected in sperm of wild type animals at such low cycle numbers.

The presence of RNA molecules has been reported in human sperm (reviewed in ref._16). The finding of increased amounts in heterozygotes was not expected and needed confirmation. Acridine-orange staining showed two unexpected features in heterozygous and paramutated males (Fig. 4b). Microscopic examination revealed the accumulation of yellow stained material in the vicinity of their nuclei, presumably corresponding to RNA ${ }^{17}$. FACS diagrams confirmed a significant degree of yellow staining (vertical axis). On the other hand, a more variable intensity of the green stain (DNA, horizontal axis) was indicative of a less compact chromatin structure.

RNA containing structures can be identified in the electron microscope by the EDTA regressive staining technique, based on the chelation of uranyl ions by neutral EDTA ${ }^{18,19}$. EDTA regressive staining in an Epon section shows densely contrasted structures corresponding to ribonucleoprotein constituents, while DNA containing structures appear greyish or bleached (see control spermatocyte sections in Fig. 4c). Enzymatic treatment of the sections (not shown) verified that the EDTA 
regressive staining was abolished after RNase treatment and remained unchanged after extensive treatment of the sections with either DNase I or pronase.

Spermatozoa in epididymis sections (Fig. 4c) showed characteristic staining patterns for Kit $^{\text {tml Alf } /+}$ heterozygotes with heads more heterogeneous and more contrasted than those of B6D2 males. The generally light staining of the wild type mouse sperm by the EDTA regressive technique, with only the rare occurrence of somewhat more contrasted sections (Fig. 4c), may reflect a physiological low level of RNA, as reported for human sperm ${ }^{16}$. It was clearly distinct from the homogeneous staining of sperm heads in heterozygotes, which taken together with RT-PCR results and with the deregulated expression of Kit at the late spermatogenic stages, was indicative of the presence of unusual amounts of RNA.

\section{RNA induction}

The presence of RNA in sperm cells led us to consider the possibility that transfer of RNA to the fertilized egg could be the signal leading to the paramutated phenotype. Although the molecular mechanisms involved would remain to be established, such a hypothesis would be consistent with recent examples of RNA molecules responsible for stable epigenetic changes (reviewed in ref. 20). A series of experiments were performed in which RNA prepared from either $\mathrm{Kit}^{+/+}$homozygotes or

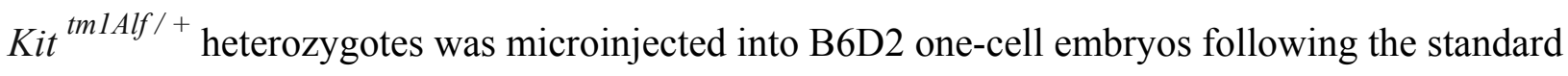
procedures of DNA microinjection ${ }^{21}$. No toxicity was noted and, in every litter born after Kit ${ }^{\operatorname{tm} 1 \mathrm{Alf} /+}$ RNA injection, a fraction of the offspring close to $50 \%$ showed the white tail tip characteristic of the heterozygote (Fig. 5). The same result was registered after injection of somatic (brain) RNA and of RNA prepared from heterozygote sperm. We noted, however, the appearance of rare white-spotted mice in the control litters produced after microinjection of RNA prepared from wild type brain, as well as after injection of irrelevant (LacZ) RNA. We nevertheless concluded that this was a specific effect of the heterozygote RNA for two reasons. First, the frequencies in these controls were significantly lower than with heterozygote RNA, with smaller white areas. More significantly, the rare white tail phenotype of the controls were either very inefficiently or not at all transmitted to the 
progeny in crosses with wild type partners, in clear contrast with the phenotype induced by Kit ${ }^{\text {tmlalf/ }}$ RNA, which was efficiently transmitted (Fig. 5 and Supplementary Table 3).

Taken together with the presence of RNA molecules of abnormal sizes in preparations from heterozygotes (Fig. 2), we hypothesized that the paramutated state was induced by a partial degradation product of Kit RNA. We then attempted to target RNA degradation by injecting either one of the two microRNAs, miR-221 and -222 , which had been identified as potentially targeting Kit mRNA in a computational survey of mammalian microRNAs ${ }^{22}$. We then tested whether injection of these two miRNAs could have the same effect. This experiment proved that this is indeed the case with the white tail phenotype being induced at high frequency and efficiently inherited (Fig. 5b, Supplementary Table 2). Exposure to microRNAs of the early embryonic genome thus appears sufficient to induce a permanent and heritable epigenetic change in gene expression.

\section{Conclusion}

While it is tempting to think in term of causal relationships, the mechanisms leading to the inherited modification of the paramutated phenotype and to the similar phenotypes induced by exposure to the abnormal species of Kit RNA and to microRNAs remain to be precised. Further characterization of RNAs in heterozygotes, of their effects when injected into zygotes, as well as of the mechanistic aspects of the chromatin remodeling processes directed by microRNAs, will hopefully lead to a more complete and better defined picture.

The initial event inducing paramutation is not known, even in the most thoroughly investigated plant systems ${ }^{2}$. Incomplete meiotic pairing of homologous chromosomes is considered as the determining event in the epigenetic changes known as co-suppression in plants and meiotic silencing in Neurospora ${ }^{23}$. Preliminary results on two other Kit mutants would be consistent with this view. We generated a distinct insertion mutant carrying a GFP-Neo cassette in the first intron of the gene and found that paramutated animals were generated in progenies under the same conditions and with the same frequency as in Kit ${ }^{\text {tmlAlf } /+^{+}}$crosses. To the contrary, strictly Mendelian phenotypic and 
genotypic segregations were consistently found in the offspring of the classical point mutant Kit ${ }^{W-v} 24$ (data not shown).

A number of epigenetic determinations are currently under study in various systems, and a role of RNA has been suggested in several instances (reviewed in ref. 2), the induction of heritable phenotypic changes by double stranded RNA was reported in Coenorhabditis elegans ${ }^{25}$ and a RNA cache was suggested as a carrier of genetic information in Arabidopsis $^{26}$. On the other hand, one of the challenging aspects of the present results is the hereditary transmission of epigenetic states. Paternal and maternal transmission was equally efficient. Analysis of the sperm cell, of a simpler structure than the ovocyte, led us to conclude that it is not only a vector for the male haploid genome but also the carrier of supplementary information in the form of RNA molecules. The EDTA regressive technique, which allows the analysis of spermatozoa at the cellular level, and on the other hand, microinjection into fertilized eggs of RNA and microRNAs should be useful tools to develop a functional analysis. The mouse model might then provide a clue on the function of the RNA molecules that are observed in human sperm ${ }^{16}$. The hypothesis that RNAs of paternal origin, including microRNAs, can play a role in modulating gene expression in the embryo has been recently formulated (reviewed in ref. 16) and paramutation in the Kit gene may provide a useful experimental model for further analysis.

\section{Methods}

Mice and genetic typing. Kit ${ }^{\text {tm } I A l f /+}$ heterozygotes were initially received from Dr. J.J. Panthier (Institut Pasteur, Paris). Three stocks were generated and maintained in parallel, one in the original 129/Sv genetic background, and two by crosses into C57BL/6 and into C57BL/6 x DBA/2 (B6D2), in both cases for at least 6 generations. We determined genotypes by PCR assays specific for the Neo and $L a c Z$ transgene and by Southern blot hybridization with a genomic probe. Investigations were conducted in accordance with French and European regulations for the care and use of research animals.

Southern blot analysis. Analysis was performed after cleavage with EcoRI and EcoRV enzymes as described ${ }^{5}$. 
RNA analysis. Northern analysis was performed as previously described ${ }^{3}$. Polyadenylated RNA was prepared from total RNA using the mRNA Isolation Kit (Roche Molecular Biochemicals) according to manufacturer's instructions. The 5' probe for detection of Kit mRNA covered the distal part of exon 1 and exon 2, from nt 69 to 374 of the cDNA sequence (GenBank AY536430). The probe for the 3' part of the Kit transcript and the mRNA encoding the truncated tr-Kit ${ }^{14}$ extended from nt 2418 to 2776 (see supplementary data for nucleotide sequences). Quantitation was performed by densitometric analysis of autoradiograms at various exposure times. Kit RNA values were normalized to the level of GAPDH mRNA. Quantitative PCR assays were performed with the ABI Prism apparatus (AB Applied systems) with the Syber Green I kit (Eurogentec ref. RT-SN2x-03+). Sequences of oligonucleotide primers are provided as Supplementary Material.

Transcriptional run-on assays. Assays of transcriptional activity by radiolabeling of RNA transcripts with $\left[\alpha-{ }^{32} \mathrm{P}\right] \mathrm{UTP}$ in isolated nuclei ${ }^{27}$ were performed on testicular cell preparations from 10 week-old males. Five independent assays per animal were performed on two animals of each genotype. A detailed procedure is provided as Supplementary Information linked to the online version of the paper.

Acridine Orange staining and FACS analysis. Preparation of spermatozoa from the epididymis of wild type, heterozygote and paramutated males were fixed in buffered $10 \%$ formaldehyde for $30 \mathrm{~min}$, rinsed with phosphate-buffered saline, treated with trypsin $0,2 \%$ and $0,01 \%$ Triton-X100 for 30 min at room temperature, washed and stained with Acridine Orange (Sigma A6014) for 15 min according to published procedures ${ }^{17}$. Samples were analyzed on a CAS200 apparatus (Becton-Dickinson Cell Analysis System, Elmhurst, Illinois).

Microinjection into fertilized eggs. RNA microinjection into B6D2 fertilized eggs (after normal ovulation) was performed by the standard techniques of DNA injection ${ }^{21} .1-2 \mathrm{pl}$ of a $10 \mu \mathrm{g} / \mathrm{ml}$ solution of total RNA and of $0.1 \mu \mathrm{g} / \mathrm{ml}$ solutions of RNA oligonucleotides in Tris 5mM EDTA 0.1 $\mathrm{mM}$ were injected. 
In situ determination of $\beta$-galactosidase activity. $X$-Gal determination of $\beta$-galactosidase activity was performed as previously described ${ }^{28}$.

Electron microscopy. Mouse testes and epididymis were fixed immediately after dissection in $1.6 \%$ glutaraldehyde in $0.1 \mathrm{M}$ phosphate buffer $\left(1 \mathrm{~h}, 4^{\circ} \mathrm{C}\right)$. They were rinsed with buffer and free aldehyde groups were blocked with $50 \mathrm{mM} \mathrm{NH} \mathrm{Cl}_{4}$ in $\mathrm{PBS}$ for 30 min at $4^{\circ} \mathrm{C}$. Specimens were dehydrated with acetone and embedded in Epon. RNA-protein complexes were visualized by the EDTA regressive technique $^{18}$. Shortly, grids were stained 1 min with $4 \%$ aqueous solution of uranyl acetate (RT) and treated $30 \mathrm{~min}$ in $0.2 \mathrm{M}$ EDTA solution $\mathrm{pH} 7.0$. Grids were carefully rinsed with distilled water and stained with 1 min with lead citrate. Under these conditions, only RNA molecules remained stained. All grids were observed in a Philips CM12 electron microscope operating at 60 or $80 \mathrm{kV}$ and equipped with a $30 \mu \mathrm{m}$ objective aperture. Recording films were taken and treated under similar working conditions.

1. Brink, R. A. A genetic change associated with the $R$ locus in maize which is directed and potentially reversible. Genetics 41, 872-879 (1956).

2. Chandler, V. L. \& Stam, M. Chromatin conversations: mechanisms and implications of paramutation. Nat Rev Genet 5, 532-544 (2004).

3. Rassoulzadegan, M., Magliano, M. \& Cuzin, F. Transvection effects involving DNA methylation during meiosis in the mouse. Embo J 21, 4404-50 (2002).

4. Herman, H. et al. Trans allele methylation and paramutation-like effects in mice. Nat Genet 34, 199-202 (2003).

5. Bernex, F. et al. Spatial and temporal patterns of c-kit-expressing cells in $W^{\text {lac } Z /+}$ and

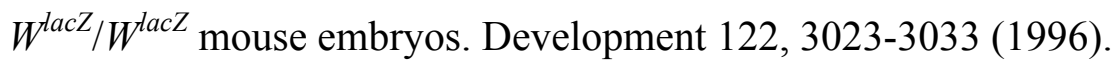

6. Yasuda, H., Galli, S. J. \& Geissler, E. N. Cloning and functional analysis of the mouse c-kit promoter. Biochem Biophys Res Commun 191, 893-901 (1993).

7. Olek, A., Oswald, J. \& Walter, J. A modified and improved method for bisulphite based cytosine methylation analysis. Nucleic Acids Res 24, 5064-5066 (1996). 
8. Lachner, M. \& Jenuwein, T. The many faces of histone lysine methylation. Curr Opin Cell Biol 14, 286-298 (2002).

9. Kluppel, M., Nagle, D. L., Bucan, M. \& Bernstein, A. Long-range genomic rearrangements upstream of Kit dysregulate the developmental pattern of Kit expression in W57 and Wbanded mice and interfere with distinct steps in melanocyte development. Development 124, 65-77 (1997).

10. Manova, K., Nocka, K., Besmer, P. \& Bachvarova, R. F. Gonadal expression of c-kit encoded at the W locus of the mouse. Development 110, 1057-1069 (1990).

11. Motro, B., van der Kooy, D., Rossant, J., Reith, A. \& Bernstein, A. Contiguous patterns of ckit and steel expression: analysis of mutations at the W and S1 loci. Development 113, 1207-1221 (1991).

12. Sorrentino, V., Giorgi, M., Geremia, R., Besmer, P. \& Rossi, P. Expression of the c-kit protooncogene in the murine male germ cells. Oncogene 6, 149-151 (1991).

13. Vincent, S. et al. Stage-specific expression of the Kit receptor and its ligand (KL) during male gametogenesis in the mouse: a Kit-KL interaction critical for meiosis. Development 125, 4585-4593 (1998).

14. Albanesi, C. et al. A cell- and developmental stage-specific promoter drives the expression of a truncated c-kit protein during mouse spermatid elongation. Development 122, 1291-1302 (1996).

15. Turner, J. M. et al. Silencing of unsynapsed meiotic chromosomes in the mouse. Nat Genet 37 , $41-47(2005)$.

16. Krawetz, S. A. Paternal contribution: new insights and future challenges. Nature Rev. Genetics, 6, 633-642 (2005).

17. Darzynkiewicz, Z. Differential staining of DNA and RNA in intact cells and isolated cell nuclei with acridine orange. Methods Cell Biol 33, 285-298 (1990).

18. Bernhard, W. A new staining procedure for electron microscopical cytology. J Ultrastruct Res 27, 250-265 (1969). 
19. Biggiogera, M. \& Fakan, S. Fine structural specific visualization of RNA on ultrathin sections. J Histochem Cytochem 46, 389-395 (1998).

20. Bernstein, E. \& Allis, C. D. RNA meets chromatin. Genes Dev 19, 1635-55 (2005).

21. Hogan, B., Costantini, F. \& Lacy, L. Manipulating the mouse embryo - a laboratory manual (Second edition, Cold Spring Harbor Laboratory, Cold Spring Harbor, NY, 1994).

22. Lewis, B. P., Shih, I. H., Jones-Rhoades, M. W., Bartel, D. P. \& Burge, C. B. Prediction of mammalian microRNA targets. Cell 115, 787-798 (2003).

23. Shiu, P. K., Raju, N. B., Zickler, D. \& Metzenberg, R. L. Meiotic silencing by unpaired DNA. Cell 107, 905-916 (2001).

24. Nocka, K. et al. Molecular bases of dominant negative and loss of function mutations at the murine c-kit/white spotting locus: W37, Wv,W41 andW. EMBO J. 9, 1805-1813 (1990).

25. Fire, A. et al. Potent and specific genetic interference by double-stranded RNA in Caenorhabditis elegans. Nature 391, 806-811 (1998).

26. Lolle, S. J., Victor, J. L., Young, J. M. \& Pruitt, R. E. Genome-wide non-mendelian inheritance of extra-genomic information in Arabidopsis. Nature 434, 505-509 (2005).

27. Sambrook, J. \& Russell, D. W. Molecular cloning: a laboratory manual (Cold Spring Harbor Laboratory Press, Cold Spring Harbor, N.Y., 2001).

28. Sage, J. et al. Temporal and spatial control of the Sycp1 gene transcription in the mouse meiosis: regulatory elements active in the male are not sufficient for expression in the female gonad. Mech Dev 80, 29-39 (1999). 
Supplementary Information is linked to the online version of the paper at www.nature.com/nature.

Acknowledgments. We are indebted to K. Thyagarajan for her participation in experimental work, to J.J. Panthier for the gift of the Kit ${ }^{\text {tml Alf } /+}$ mouse and for helpful discussions, to K.B. Marcu and A. Schedl for editorial help. We thank M. Aupetit, Y. Fantei-Caujolle, J.P. Laugier, S. Pagnotta and K. Rassoulzadegan for expert technical assistance. This work was made possible by a grant to M.R. as "Equipe Labellisée” of the "Ligue Nationale Française Contre le Cancer".

Correspondence should be addressed to M.R. (e-mail: minoo@unice.fr) 
Table 1. Segregation of coat phenotypes in the progeny of $\mathrm{Kit}^{\mathrm{tm} 1 \mathrm{Alf} / \mathrm{H}}$ parents

\begin{tabular}{|c|c|c|c|c|c|c|}
\hline \multicolumn{3}{|c|}{ Crosses $^{\dagger}$} & \multicolumn{4}{|c|}{ Progeny $^{\S}$} \\
\hline Male & & Female & Fur phenotype & Lac Z & Number of mice & Class \\
\hline \multirow{3}{*}{ Kit $^{\text {tm1Alf /+ }}$} & & & White-spotted & + & 30 & $K_{i t}{ }^{\text {tm1Alf } /+}$ \\
\hline & $x$ & $K_{i t}{ }^{t m 1 A l f /+}$ & White-spotted & - & 24 & Kit * \\
\hline & (8) & & Full color & - & 3 & $\mathrm{Kit}^{+/+}$ \\
\hline \multirow{3}{*}{$K_{i t}{ }^{t m 1 A l f /+}$} & & & White-spotted & + & 16 & Kit ${ }^{\text {tm1Alf } /+}$ \\
\hline & $x$ & $\mathrm{Kit}^{+/+}$ & White-spotted & - & 24 & Kit * \\
\hline & (4) & & Full color & - & 4 & $\mathrm{Kit}^{+/+}$ \\
\hline \multirow{3}{*}{$\mathrm{Kit}^{+/+}$} & & & White-spotted & + & 22 & $\mathrm{Kit}^{\mathrm{tm} 1 \mathrm{Alf} /+}$ \\
\hline & $x$ & $K_{i t}{ }^{\text {tm1Alf /+ }}$ & White-spotted & - & 14 & Kit * \\
\hline & (4) & & Full color & - & 5 & $\mathrm{Kit}^{+/+}$ \\
\hline \multirow[t]{2}{*}{ Kit * } & $x$ & $\mathrm{Kit}^{+/+}$ & $\begin{array}{l}\text { White-spotted } \\
\text { (partially) }^{\$}\end{array}$ & nd & 26 & Kit * \\
\hline & (6) & & Full color & nd & 40 & $\mathrm{Kit}^{+/+}$ \\
\hline \multirow[t]{2}{*}{$\mathrm{Kit}^{+/+}$} & $x$ & Kit * & $\begin{array}{l}\text { White-spotted } \\
\text { (partially) } \$\end{array}$ & nd & 23 & Kit * \\
\hline & (5) & & Full color & nd & 34 & $\mathrm{Kit}^{+/+}$ \\
\hline \multicolumn{7}{|c|}{ B6D2 genetic background; number of litters analyzed shown in parenthesis. } \\
\hline \multicolumn{7}{|c|}{$\begin{array}{l}\S \text { Phenotype: see Fig. } 1 \mathrm{~b} \text { and Supplementary Fig. 1; genotyping: LacZ determination by genomic PCR } \\
\text { amplification and expression by X-Gal assay on tail; nd: not determined. }\end{array}$} \\
\hline
\end{tabular}




\section{Legends to figures}

Figure 1. The "White Spotted" phenotype of Kit ${ }^{\text {tm1Alf/+ }}$ heterozygotes and their paramutated progeny. a. Genotype and phenotype of the heterozygote. El: EcoRI, EV: EcoRV sites. b. Heterozygote and paramutated $\left(\mathrm{Kit}^{*}\right)$ littermates. C. Nine mice with white tail tips from 3 litters were further analyzed by Southern blot hybridization with a probe amplified from nt -904 to +89 of the Kit locus ${ }^{5}$. DNA in lanes 2 to 6,8 and 9 show the wild type genomic structure (Kit* paramutated); lanes 1 and 7: Kit ${ }^{\text {tm1Alf /+ }}$ heterozygotes; lane 10: control B6D2 DNA.

Figure 2. Monoallelic levels of polyadenylated Kit RNA and abnormal patterns in total RNA. a. Northern analysis of brain mRNA and densitometric measurements performed at successive exposure times of the Kit mRNA band relative to Gapdh in the same lane. Ordinate: arbitrary values shown as mean \pm s.e.m., $\star$ : significant $(p<0.05)$. b. Northern analysis of $\mathrm{Kit}^{\text {tm1Alf /+ }}$ total RNA compared to Kit ${ }^{+/+}$RNA shows a variety of additional transcripts with different patterns in different organs. The 5' Kit probe covers exons 1 and 2, and the LacZ probe, the entire coding region.

Figure 3. Kit RNA is overexpressed in heterozygote germ cells. a. Increased transcription rate. Incorporation of $\alpha\left[{ }^{32} \mathrm{P}\right] \mathrm{UMP}$ in permeabilized testicular cells and radioactivity determination in hybrids with a Kit probe, relative to total incorporation (arbitrary units, see Methods). b. Northern blot analysis with the 5' Kit probe of RNA prepared from elutriation fractions (90 per cent pure ${ }^{13}$, starting from pools of 10 males of each genotype): "Rs": round spermatids; "Es": elongated spermatids; "Es+S": a mixture of elongated spermatids and spermatozoa. Hybridization with protamine (Prm1) probe (control) and with the 3' Kit probe to detect the truncated form $\mathrm{tr}-\mathrm{Kit}^{14}$.

Figure 4. RNA in Kit ${ }^{\text {tm1Alf/+ }}$ spermatozoa. a. DAPI staining, RT-PCR determination of Kit RNA (1-3: wild type; 4-6: heterozygotes); quantitative real time PCR determination relative to Gapdh RNA. b. Acridine-orange staining: fluorescence microscopy and FACS analysis of 
RNA (yellow, vertical axis) and DNA (green, horizontal axis); values in red and blue: cell counts in the corresponding compartment. c. EDTA regressive staining. Top: Kit ${ }^{\text {tm1Aff/+ }}$, bottom: $\mathrm{Kit}^{+/+}$, left: epididymis (insert: higher magnification), right: control staining of spermatocytes, showing the greyish appearance of nuclei (DNA) and the contrasted stain (RNA) in cytoplasm. Bar: $1 \mu \mathrm{m}$.

Figure 5. A heritable mutant-like phenotype induced by RNA microinjection in one-cell embryos. a. White-spotted progeny (per cent, total number shown in parenthesis) born after microinjection of the indicated RNAs (sequences of oligonucleotide primers and miRNAs listed as Supplementary data). Horizontal lines: average with s.e.m. of each group $(\star p<0.05)$. Open bars: low efficiency of transmission $(\leq 3$ per cent); closed bars: efficiencies of transmission from 56 to 78 per cent (complete data listed in Supplementary Table 2). b. F1 progeny of a wild type female mated with a white-spotted male born after injection of Kit $^{\text {tm1Alf/+ }}$ brain RNA. 
a
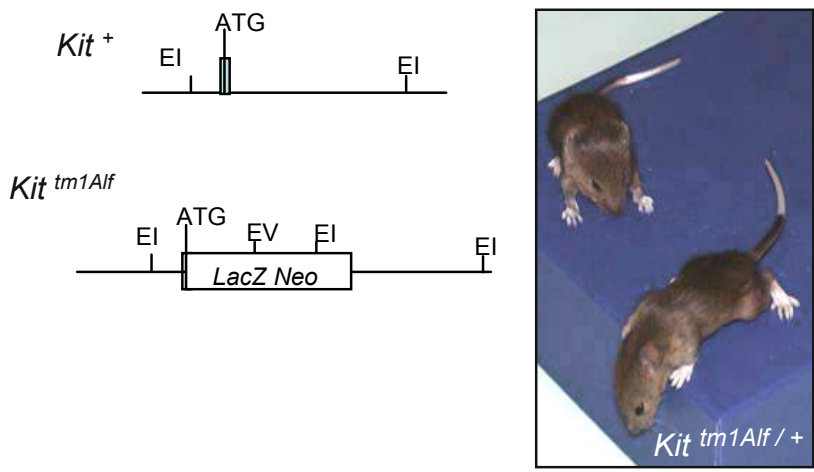

b

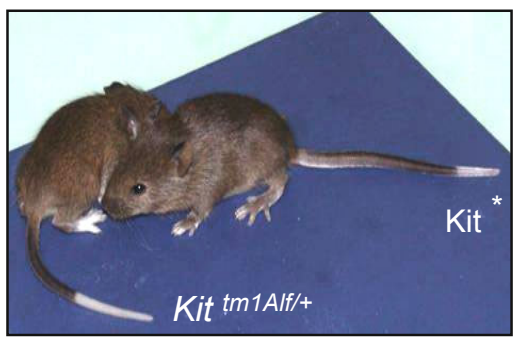

C

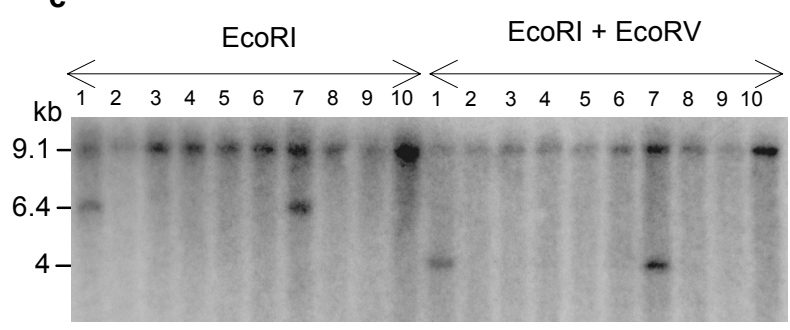

2005-06-06392CFig1 


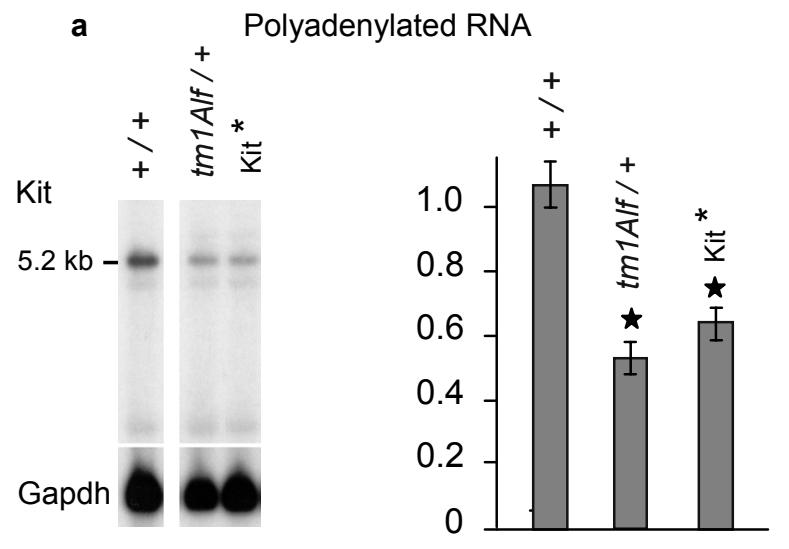

b

Total RNA

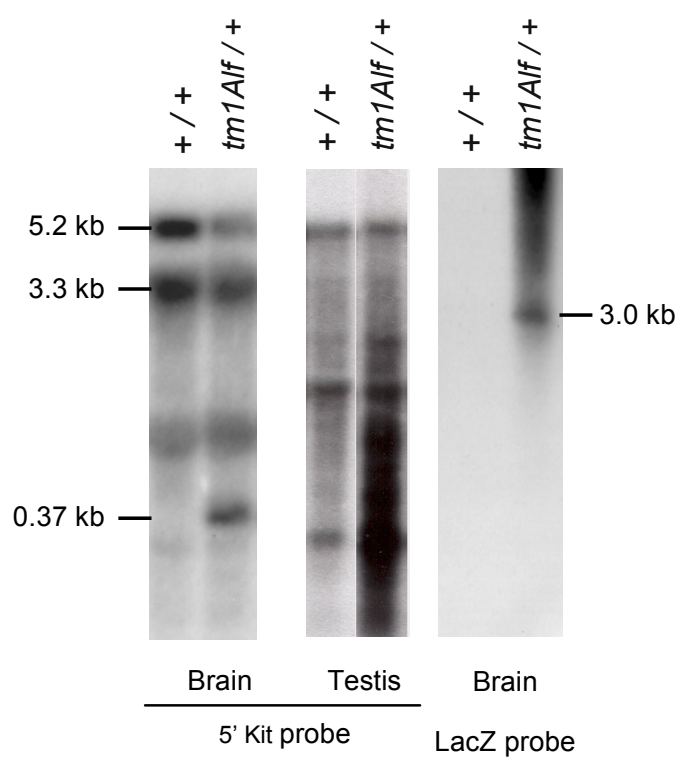


a

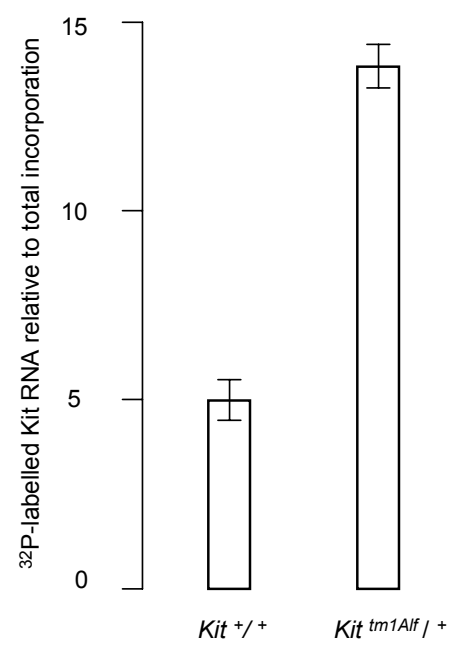

b

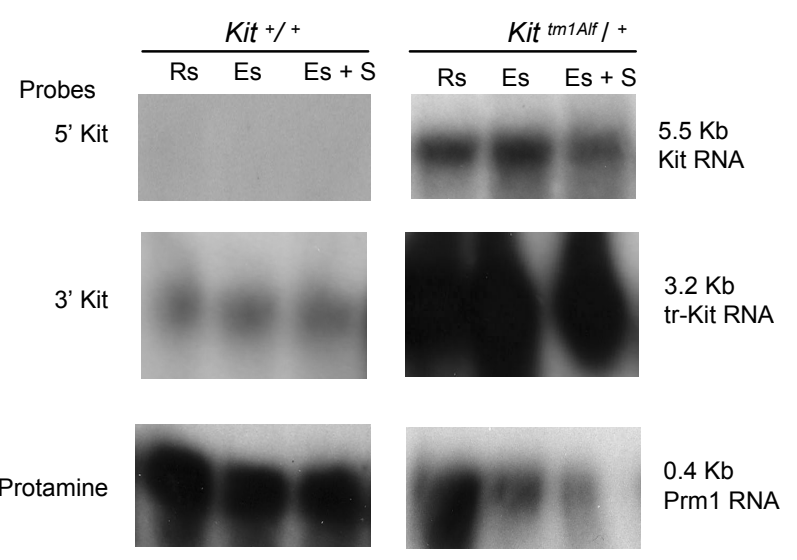

2005-06-06392CFig3 

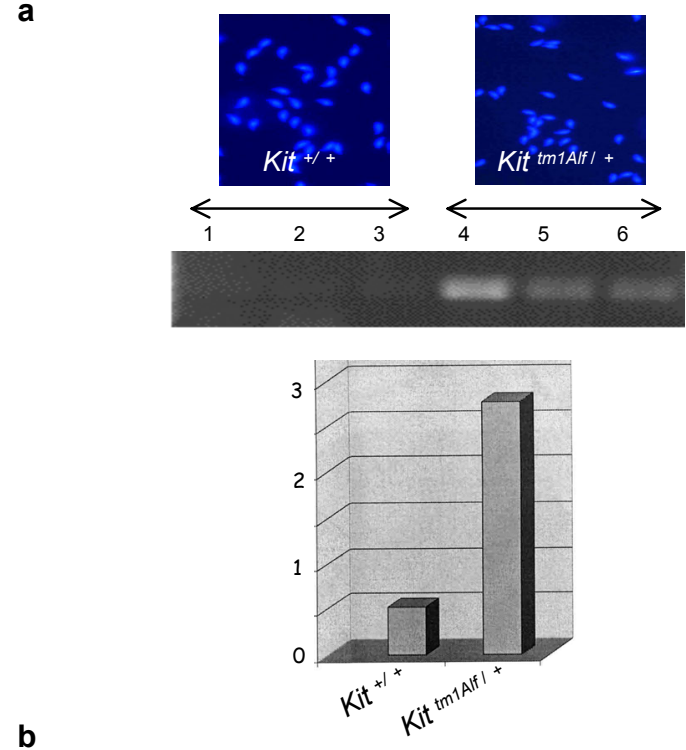

b
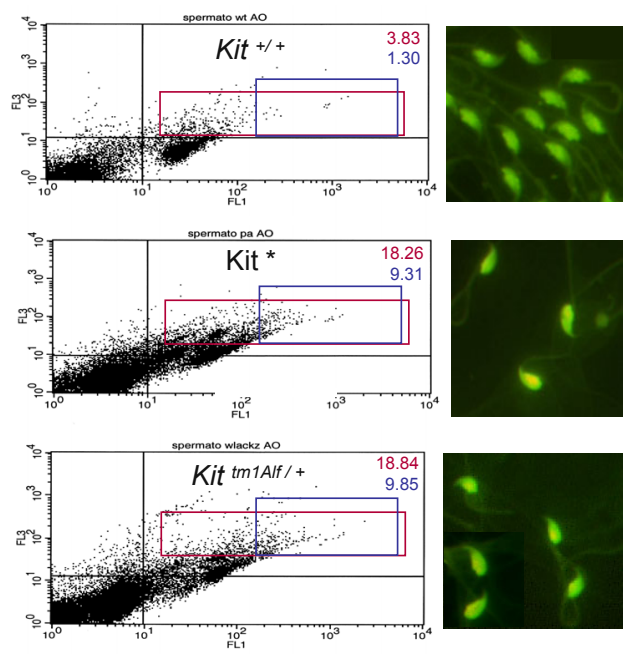

c
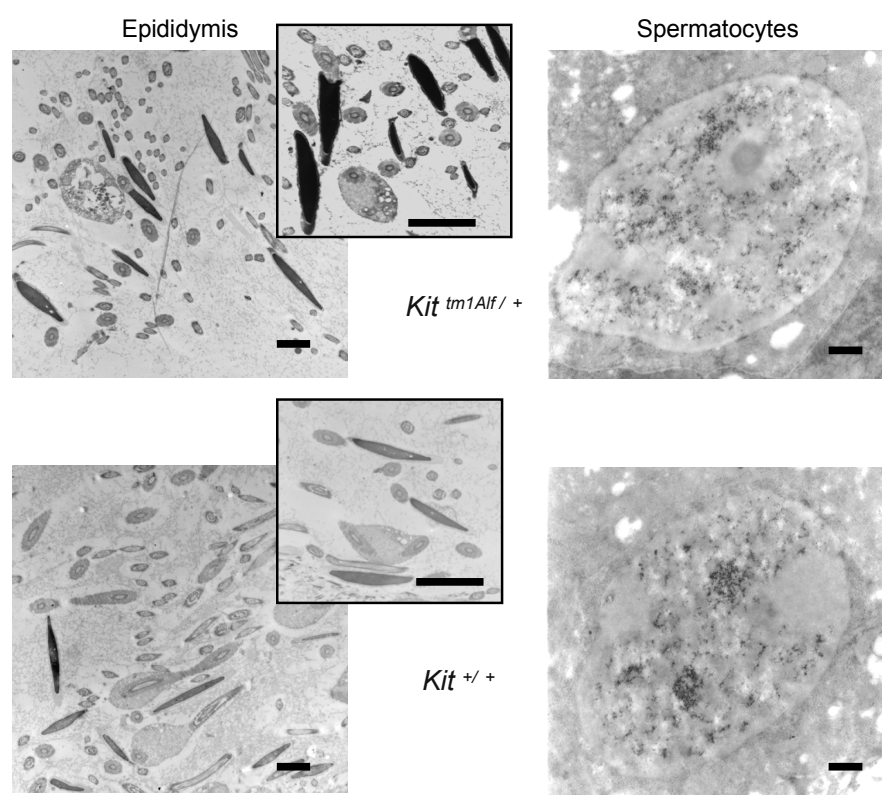


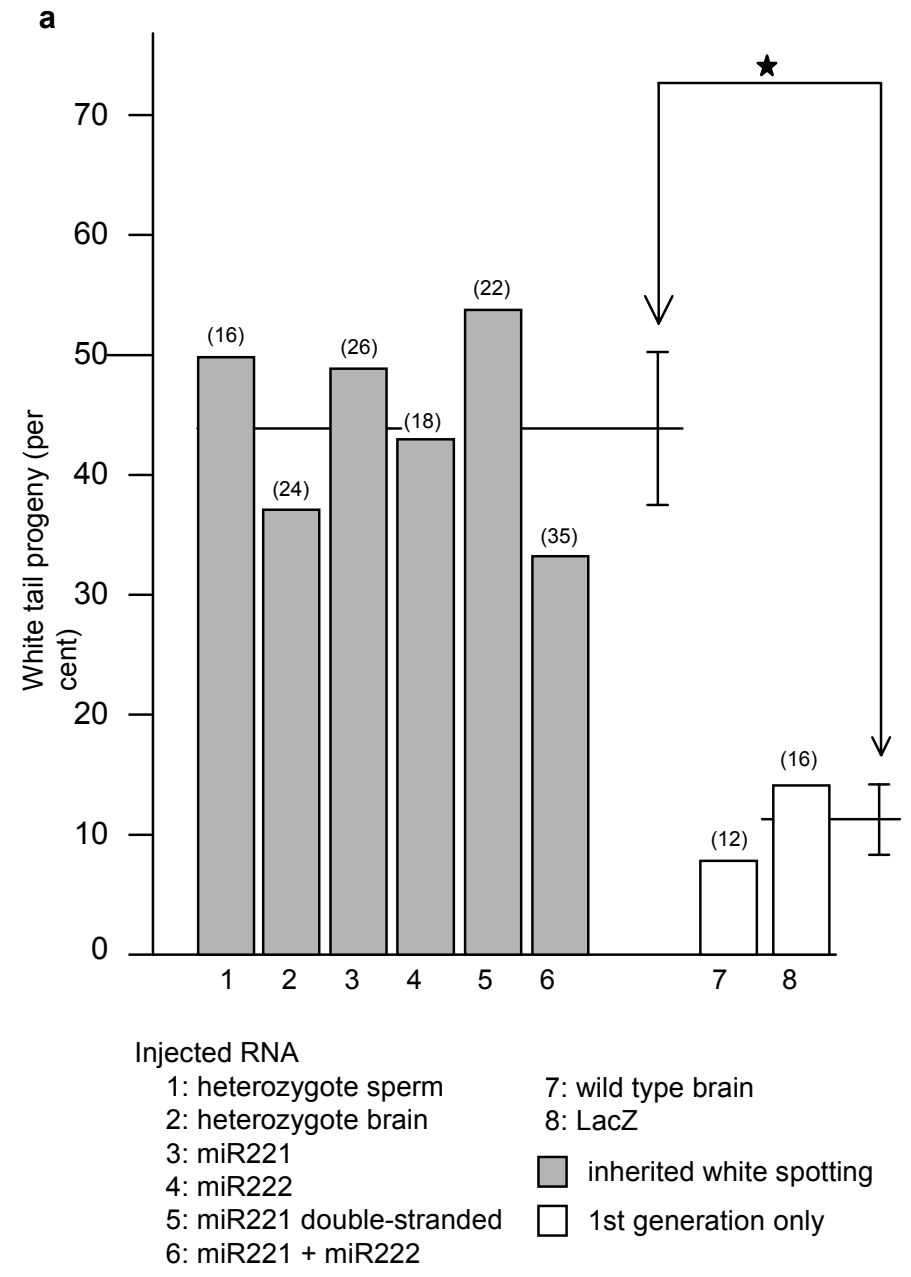

b

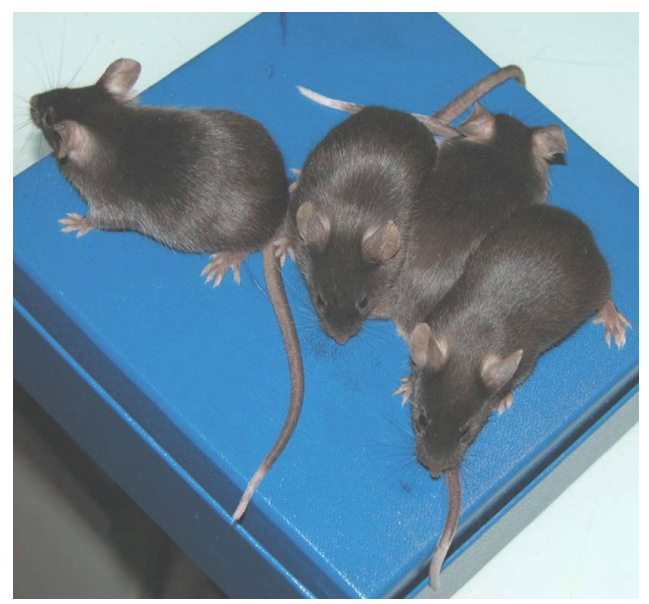




\section{Supplementary Table 1. Paternal and maternal transmission of paramutated alleles in 129/Sv and C57BL/6 genetic backgrounds}

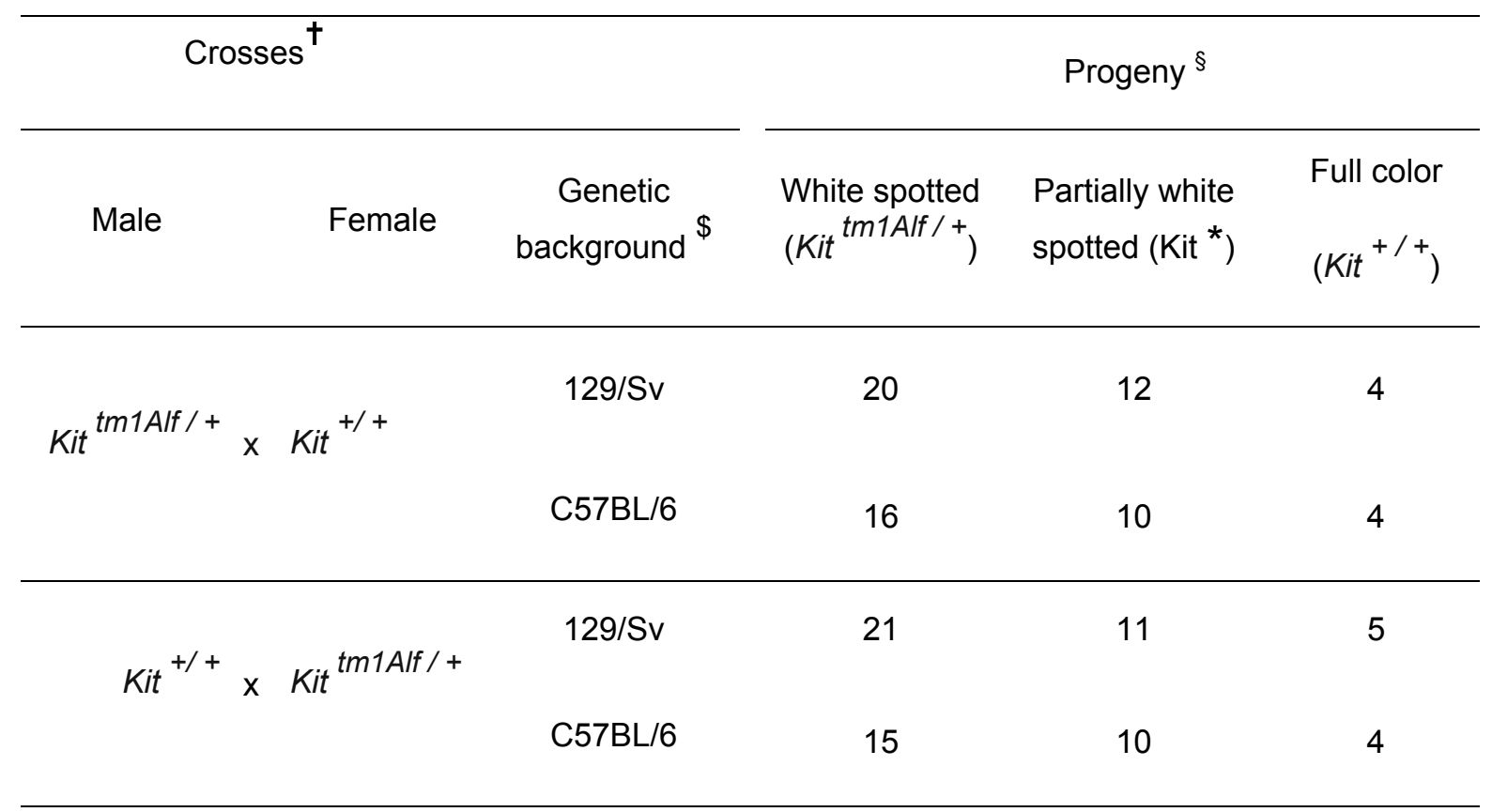

$\dagger_{\text {wild type and mutant partners of same genetic background in each cross }}$

$\S$ cumulated values of 4 litters for each cross; genotypes (parenthesis) and phenotypes of progenies as determined in Table 1

\$129/Sv: the original Kit ${ }^{\text {tm1Alf } /+}{ }^{\text {strain }}{ }^{7}$; C57BL/6: at least 6 backcrosses of the mutant allele. 


\section{Supplementary Table 2. Inheritance of the white-spotted phenotype induced by RNA microinjection}

\begin{tabular}{|c|c|c|c|}
\hline Injected RNA & $\begin{array}{l}\text { Mating partners } \\
\text { (wild type) }\end{array}$ & $\begin{array}{c}\text { White-spotted progeny } \\
\text { / total }^{\dagger}\end{array}$ & $\begin{array}{c}\text { Transmission efficiency } \\
\text { (per cent) }\end{array}$ \\
\hline Paramutated brain & female & $25 / 32$ & 78 \\
\hline RNA & male & $26 / 34$ & 76 \\
\hline \multirow{3}{*}{$\operatorname{miR} 221$} & female & $18 / 32$ & 56 \\
\hline & & & \\
\hline & male & 19/31 & 61 \\
\hline \multirow{3}{*}{$\operatorname{miR} 222$} & female & $20 / 36$ & 56 \\
\hline & & & \\
\hline & male & $18 / 32$ & 56 \\
\hline \multirow{3}{*}{ LacZ } & female & $0 / 31$ & $<3$ \\
\hline & & & \\
\hline & male & $1 / 33$ & 3 \\
\hline $\begin{array}{l}\text { Wild type brain } \\
\text { RNA } \S\end{array}$ & female & $1 / 43$ & 2 \\
\hline \multicolumn{4}{|c|}{$\dagger_{\text {cumulated results of four to five litters }}$} \\
\hline
\end{tabular}




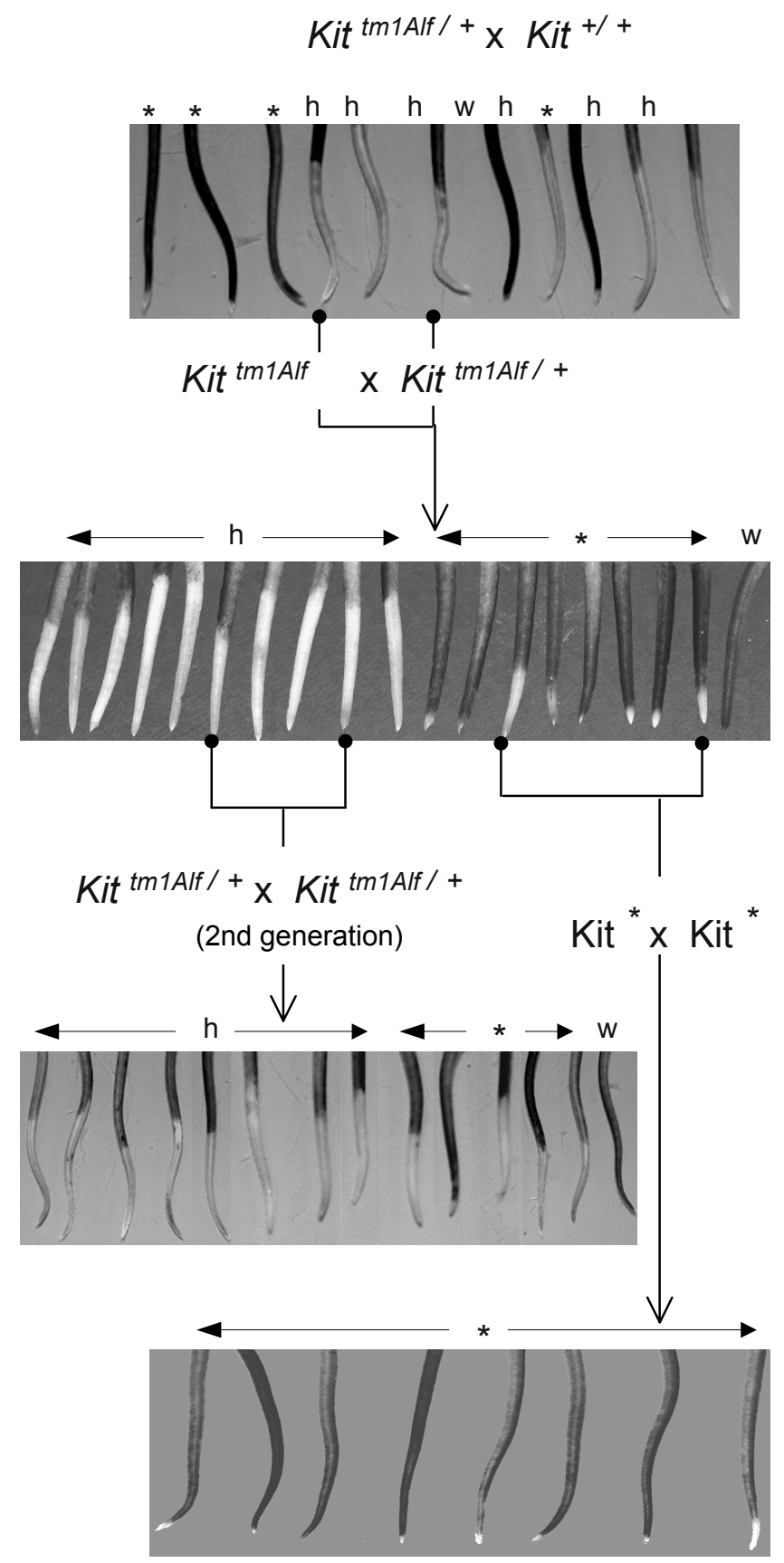

2005-06-06392CSupplFig.1 


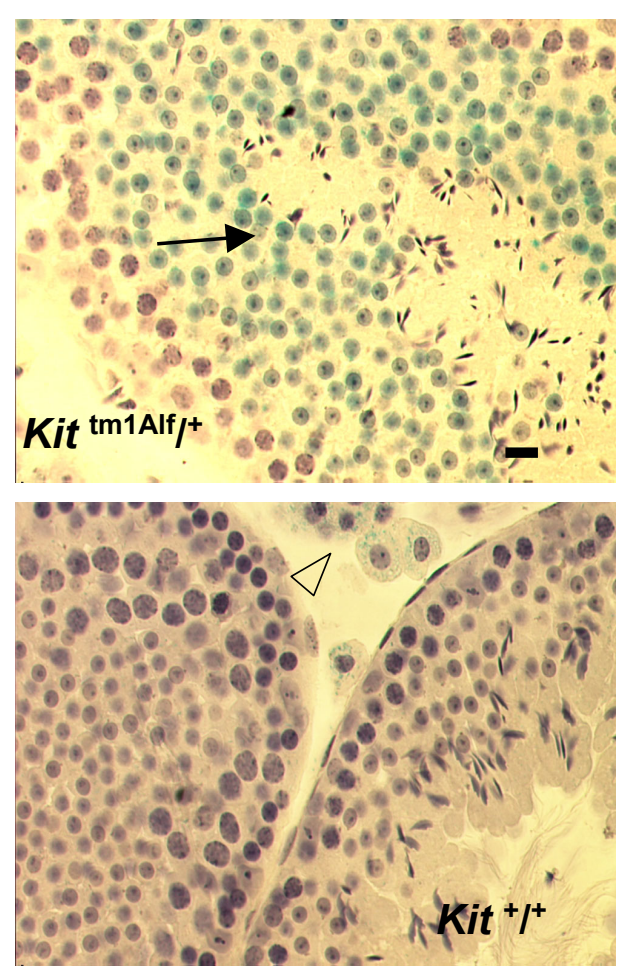

2005-06-06392CSupplFig.2 
Supplementary Figure 1. Inheritance of the white tail phenotype in crosses between

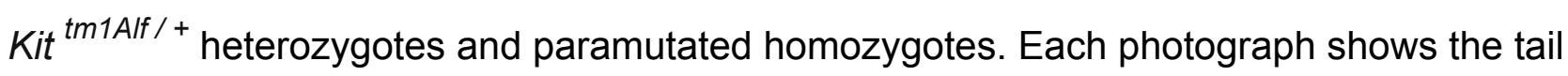
colors in either one or, in the second row from top, two litters. Genotyping (PCR determination of $\mathrm{NeO}$ and $\mathrm{LacZ}$ sequences, expression of $B$-galactosidase) compared to white tail phenotype distinguish wild type ("w"), paramutated (“*”) and heterozygotes ("h").

Supplementary Figure 2. Altered regulation of Kit transcription in the male germ cells of

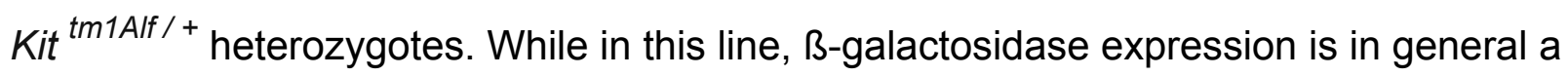
faithful reporter of the Kit promoter activity ${ }^{5}, \mathrm{X}$-Gal staining of 1 month-old male testis section shows high level of ß-galactosidase in round spermatids (arrow). Background estimated in a wild type section is limited to a faint staining in Leydig cells (arrowhead). Bar, $20 \mu \mathrm{m}$. 


\section{Supplementary Methods.}

Oligonucleotide primers and miR sequences. Oligodesoxyribonucleotides were provided by Eurogentech (France). Primers for RT-PCR amplification of Kit RNA (5' probe) were GATCTGCTCTGCGTCCTG and TGGCAGGATCTCTAACAAAC (nt 69 to 374). The probe for the 3' part of the Kit transcript and the mRNA encoding the truncated tr-Kit ${ }^{14}$ was similarly amplified with primers ACAGTGTATTCACAGAGATTTG and GACGTCATGAAGACTTGCTG (nt 2418 to 2776). The GAPDH probe was generated by reverse transcription and PCR amplification with primers, TGGCCTTCCGTGTTCCTAC and CCTGGTCCTCAGTGTAGCCCA and the probe for protamine (Prm l) with primers CCTTAGCAGGCTCCTG and GGCCAGATACCGATGC.

Oligoribonucleotides with the sequences of miR221 and miR 222, AGCUACAUUGUCUGCUGGGUUU and AGCUACAUCUGGCUACUGGGUCUC, (http://microrna.sanger.ac.uk/targets/) were provided by Sigma-Proligo.

Transcription run-on assay. After removal of albuginea, the cells from the seminiferous tubules were mechanically resuspended and washed twice with ice-cold PBS. The cell suspension was then clarified trough a $40 \mu$ filter to remove cellular aggregates. Suspensions from individual mice $\left(1 \times 10^{8}\right.$ cells) were resuspended in $1 \mathrm{ml}$ ice-cold lysis buffer $(10 \mathrm{mM}$ Tris- $\mathrm{HCl} \mathrm{pH} 8.4,1.5 \mathrm{mM} \mathrm{MgCl}$, $0.14 \mathrm{M} \mathrm{NaCl}$ ). Addition of $10 \mu 1$ Nonidet P-40 on ice was sufficient to lyse more than $80 \%$ of the cells in 15 minutes. Nuclei were recovered by centrifugation at $1,300 \mathrm{x}$ at $5^{\circ} \mathrm{C}$ and washed twice in $20 \mathrm{mM}$ Tris-HCl pH 8.0 buffer, $10 \mathrm{mM} \mathrm{MgCl} 2,140 \mathrm{mM} \mathrm{Kcl,} \mathrm{20 \%} \mathrm{glycerol,} 14 \mathrm{mM} ß-$ mercaptoethanol (washing buffer). Nuclei were counted and the suspension was split into 5 independent samples and incubated for 20 minutes at $30^{\circ} \mathrm{C}$ in the presence of $50 \mu \mathrm{Ci}\left[\alpha-{ }^{32} \mathrm{P}\right] \mathrm{UTP}$ per tube in labeling buffer (20mM Tris- $\mathrm{HCl} \mathrm{pH} 8.0,10 \mathrm{mM} \mathrm{MgCl}, 140 \mathrm{mM} \mathrm{KCl,} 20 \%$ glycerol $14 \mathrm{mM}$ ß-mercaptoethanol, $1 \mathrm{mM}$ each of ATP, GTP and CTP, $10 \mathrm{mM}$ phosphocreatine, $100 \mu \mathrm{g} / \mathrm{ml}$ phosphocreatine kinase). Nuclei were then recovered by low-speed centrifugation and washed twice. 
RNA was prepared by the Trizol procedure, ethanol precipitated, redissolved in $50 \mu 1$ water, and total incorporated radioactivity was determined. Fixed amounts of labeled material were hybridized on excess of Kit DNA spotted onto nylon membranes under the same conditions as for Northern analysis. 